Jahrbuch für Geschichte Lateinamerikas

Anuario de Historia de América Latina

57 | 2020 | 4-14

\title{
Christoph Rosenmüller
}

Middle Tennessee State University

Murfreesboro

Introducción: Los imperios ibéricos.

Cambios, negociaciones desiguales y

autoridad
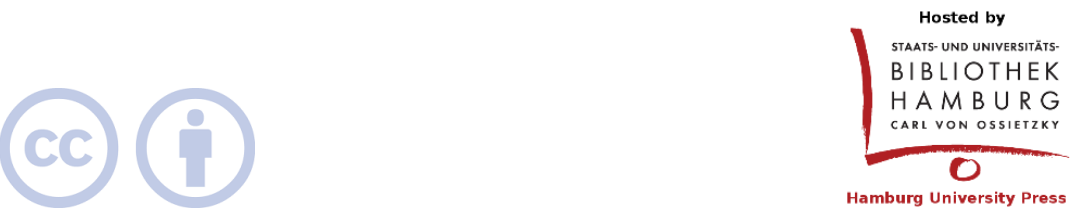

Except where otherwise noted, this article is licensed under a Creative Commons Attribution 4.0 International license (CC BY 4.0)

https://doi.org/10.15460/jbla.57.194 


\title{
Introducción: Los imperios ibéricos. Cambios, negociaciones desiguales y autoridad
}

\author{
Christoph Rosenmüller
}

\begin{abstract}
Scholars have paid much attention to the concept of the empire. Some emphasize the changing nature of the Iberian empires, while others draw attention to their pervasive and enduring structures. The articles in this dossier argue from different perspectives that the crown gradually achieved change in its favor although in limited aspects. The Crown negotiated with local groups or corporations, nudging and rewarding loyal vassals, while also threatening and punishing recalcitrants. According to the authors, this process was underway in the late sixteenth century, well before the reforms of the eighteenth century. The dossier combines contributions from specialists located in Mexico, Colombia, Chile, Portugal, and the United States for a fresh look at the challenges of empire.
\end{abstract}

Keywords: Empire, Composite Monarchy, Social Networks, Negotiations, Authority, Reforms, Viceroys.

Resumen. - El concepto del imperio ha sido objeto de gran interés en fechas recientes. Algunos historiadores y historiadoras enfatizan la naturaleza cambiante de los imperios ibéricos, mientras que otros llaman la atención sobre sus estructuras omnipresentes y duraderas. Los artículos de este dosier argumentan desde distintas perspectivas que la Corona poco a poco consiguió cambios a su favor, aunque fuera en aspectos limitados. La Corona negoció con grupos o corporaciones locales y apremió a vasallos leales, pero también amenazó y castigó a los opositores recalcitrantes. Según los textos de este dosier, ese proceso estaba ocurriendo a finales del siglo XVI, es decir, antes que las conocidas reformas del siglo XVIII. El dosier reúne contribuciones de especialistas de México, Colombia, Chile, Portugal y EE. UU. para ofrecer una nueva mirada a los desafíos del imperio.

Palabras clave: imperio, monarquía compuesta, redes sociales, negociaciones, autoridad, reformas, virreyes. 
En los últimos años, la historiografía ha agudizado nuestra conciencia sobre la estructura multicéntrica y negociada de los imperios ibéricos y su larga duración. Sin embargo, también hay historiadores que optan por explicar los cambios imperiales a través del tiempo y llaman la atención sobre las reformas y decisiones autoritarias. El objetivo de este dosier es acercarse a esa encrucijada entre negociaciones y acciones autoritarias que alteraron o preservaron los imperios. Por lo menos algunos artículos indican que gradualmente se llevaron a cabo reformas de diversas índoles, incluso en la Iglesia, aunque en aspectos limitados que a veces fracasaron. Según los autores, ese proceso ya estaba en marcha hacía finales del siglo XVI, es decir, antes que las bien estudiadas reformas del siglo XVIII. Los colaboradores arrojan luz sobre la problemática que se presentó en ciudades capitales, el clero, redes sociales, e individuos. ${ }^{1}$

El concepto de imperio se basa hasta cierta medida en la clásica propuesta del 'Estado compuesto' o la 'monarquía compuesta', términos que H. G. Koenigsberger acunó a mediados de la década de 1970. Koenigsberger argumentó que la monarquía española consistía en "países completamente separados, divididos por mar o por otros Estados", 2 en los que las élites y el rey compartían la soberanía. Forzar una unificación de la monarquía podría traer graves consecuencias, como lo demostraron las colonias británicas en Norteamérica. ${ }^{3}$ De allí que el siguiente paso en el nivel interpretativo llegaría con la percepción del carácter multicéntrico del imperio. En 1983, James Lockhart y Stuart B. Schwartz postularon que la Nueva España (México), el Perú, y, más

\footnotetext{
${ }^{1}$ Quisiera expresar mi gratitud a la Dra. Renate Pieper, Graz, por sus sugerencias en esta introducción.

2 Helmuth G. Koenigsberger, "Monarchies and Parliaments in Early Modern Europe. Dominium Regale or Dominium Politicum et Regale": Theory and Society, 5: 2 (1978), pp. 202-203.

${ }^{3}$ Koenigsberger, "Zusammengesetzte Staaten, repräsentative Versammlungen und der amerikanische Unabhängigkeitskrieg”: Zeitschrift für Historische Forschung, 18 (1991), pp. 400-403. Nota que Allan J. Kuethe / Kenneth J. Andrien, The Spanish Atlantic World in the Eighteenth Century. War and the Bourbon Reforms. 17131796, Cambridge: Cambridge University Press, 2014, pp. 7, 48-77, aplican el concepto de "monarquía compuesta" cambiante.
} 
tarde, Brasil, formaron centros con sus propias periferias al interior de los vastos imperios. ${ }^{4}$

Una fuerte línea interpretativa ha continuado enfatizando las estructuras duraderas de los imperios. Regina Grafe y Alejandra Irigoin argumentan, por ejemplo, que a lo largo de su existencia, el Imperio español involucró a las élites como 'stakeholders' (interesados) a través de pagos regionales y transferencias inter-coloniales, ${ }^{5}$ mientras Lauren Benton nos recuerda que unificar la significativa diversidad jurisdiccional y cultural fue un proceso que generalmente avanzó de manera desigual y a velocidades variables. ${ }^{6}$ El recién fallecido investigador portugués António Manuel Hespanha añadió que herramientas teóricas como la centralización burocrática o el disciplinamiento social difícilmente pueden aplicarse a las posesiones portuguesas, ya que sus territorios incluían poco más que una cadena de puestos comerciales extendidos desde África hasta China. ${ }^{7}$

${ }^{4}$ James Lockhart / Stuart B. Schwartz, Early Latin America. A History of Colonial Spanish America and Brazil, Cambridge: Cambridge University Press, 1983. Para un análisis reciente, Manuel Herrero Sánchez, "Spanish Theories of Empire. A Catholic and Polycentric Monarchy": Jörg A. Tellkamp (ed.), A Companion to Early Modern Spanish Imperial Political and Social Thought, Brill: Leiden, 2020, pp. 1752; Jürgen Osterhammel, "The Imperial Viceroy. Reflections on an Historical Type": Jeroen Duindam / Sabine Dabringhaus (eds.), The Dynastic Centre and the Provinces. Agents and Interactions, Leiden: Brill, 2014, pp. 15-18.

5 Alejandra Irigoin / Regina Grafe, "A Stakeholder Empire. The Political Economy of Spanish Imperial Rule in America": Economic History Review, 65: 2 (2012), pp. 609-651.

6 Lauren Benton, A Search for Sovereignty. Law and Geography in European Empires. 1400-1900, Cambridge: Cambridge University Press, 2010, pp. 1-31, 280; Benton, "Introduction. Law and Empire in Global Perspective": American Historical Review, 117: 4 (2012), pp. 1092-1100; véase también Jane Burbank / Frederick Cooper, "The Empire Effect": Public Culture, 24: 2 (2012), pp. 241-242.

7 António Manuel Hespanha, "Antigo regime nos trópicos? Um debate sobre o modelo político do império colonial portugués”: J. Fragoso / M. de F. Gouvêa (eds.), $\mathrm{Na}$ trama das redes. Política e negocios no império português séculos XVI-XVIII, Rio de Janeiro: Civilização Brasileira, 2010, pp. 43-93; Colin M. MacLachlan, Imperialism and the Origins of Mexican Culture, Cambridge: Harvard University Press, 2015, p. 1, discute los orígenes multi-imperiales de "Indo-Mexico", aunque mantiene que Madrid buscó "aprovecharse de la última tecnología o los recursos y mercados". 
Como resultado de dichas aportaciones, muchos historiadores hoy concuerdan que los imperios eran pluri- o policéntricos, que conservaron gran parte de su autonomía y tradiciones o, en algunas zonas, se asemejaron a archipiélagos donde la Corona ejercía una supervisión puntual o esporádica. Además, se resalta aún más el papel de los enlaces de los reinos con varios territorios del Imperio, en vez de privilegiar la relación entre ellos y la península ibérica. ${ }^{8}$

Sin embargo, una fuerte contracorriente interpretativa destaca la naturaleza cambiante de los imperios, los cuales centralizaron, extendieron o intensificaron el poder real. Esta contracorriente, igualmente cultivada durante varias décadas, postula el crecimiento del Estado premoderno, impulsado por la rivalidad con otros imperios y la resultante presión por mejorar y aumentar sus sistemas militares, ${ }^{9}$ la necesidad de recaudar impuestos en cantidades cada vez mayores en

8 Pedro Cardim / Tamar Herzog / José Javier Ruis Ibáñez / Gaetano Sabatini, "Introducción": Cardim / Herzog / Ruis Ibáñez / Sabatini (eds.), Polycentric Monarchies. How Did Early Modern Spain and Portugal Achieve and Maintain a Global Hegemony?, Brighton: Sussex Academic Press, 2012, pp. 3-8; Jean-Frédéric Schaub, "Maritime Archipelago, Political Archipelago. The Azores under the Habsburgs (1581-1640)": Cardim / Herzog / Ruis Ibáñez / Sabatini (eds.), Polycentric Monarchies, pp. 11-26; sobre archipiélagos, véase también Elizabeth Montañez-Sanabria, "Challenging the Pacific Spanish Empire. Pirates in the Viceroyalty of Peru. 1570-1750": University of California, Davis, 2014 (tesis de doctorado), pp. 20-31. Thomas Calvo, "Trayectorias de luz y de sombra": Thomas Calvo / Aristarco Regalado Pinedo (eds.), Historia del reino de la Nueva Galicia, Guadalajara: Universidad de Guadalajara / CUCSH, 2016, pp. 493-494, aboga por un imperio compuesto de cortes y ciudades de diferentes niveles; Bartolomé Yun Casalilla, "Introducción. Entre el imperio colonial y la monarquía compuesta. Élites y territorios en la Monarquía Hispánica (ss. XVI y XVII)”: Yun Casalilla (ed.), Las redes del imperio. Élites sociales en la articulación de la Monarquía Hispánica. 1492-1714, Madrid / Sevilla: Marcial Pons / Universidad Pablo Olavide, 2009, pp. 11-13; véase también Gabriel Paquette, The European Seaborne Empires. From the Thirty Years' War to the Age of Revolutions, New Haven: Yale University Press, 2019, pp. 4, 18, enfatiza "violencia coercitiva", asimetría política y colaboración de los grupos dirigentes como principios de los imperios.

9 Thomas Ertman, Birth of the Leviathan. Building States and Regimes in Medieval and Early Modern Europe, Cambridge: Cambridge University Press, 1997, pp. 128, 34 . 
estos entornos bélicos, ${ }^{10}$ el pensamiento neo-tacitista ${ }^{11}$ y los deseos de dinastías religiosas por ordenar el Estado y disciplinar a sus oficiales. ${ }^{12}$

Publicaciones recientes sobre el Imperio español afirman que Nueva España se integró progresivamente en el Imperio español. Bernardo García Martínez, por ejemplo, propone que Castilla ejercía un dominio indirecto en la primera mitad del siglo XVI, ya que la mayoría de los pueblos sobrevivieron a la conquista en gran medida intactos. En la segunda mitad del siglo, el dominio empezó a fortalecerse, cuando se debilitaron los caciques y llegaron más alcaldes mayores. ${ }^{13}$ Horst Pietschmann afirma que también en el siglo XVIII, la territorialización avanzó a medida que las fronteras se hicieron más marcadas, los reinos más integrados, los individuos salieron de sus corporaciones y de sus antiguas normas de convivencia y la ley se hizo más uniforme. ${ }^{14}$ Por lo

10 Richard Bonney, "Early Modern Theories of State Finance": Richard Bonney (ed.), Economic Systems and State Finance, Oxford: Clarendon Press, 1995, pp. 163-231; Carlos Marichal / Matilde Souto Mantecón, "La Nueva España y el financiamiento del Imperio español en América. Los situados para el Caribe en el siglo XVIII”: Marichal / Johanna von Grafenstein (eds.), El secreto del Imperio español. Los situados coloniales en el siglo XVIII, México: El Colegio de México / Instituto Mora, 2012, pp. 61-93.

11 John H. Elliott, “A Europe of Composite Monarchies”: Past \& Present, 137 (1992), pp. 57-59; más tarde usa casi indistintamente los conceptos "imperio" y "monarquía compuesta de [...] reinos y territorios con sus distintas tradiciones y formas de gobierno"; John H. Elliott, Empires of the Atlantic World, New Haven: Yale University Press, 2006, p. 117; una lectura fundamental sobre neo-tacitismo es Gerhard Oestreich, "The Constitutional Development of the Early Modern State": Brigitta Oestreich / Helmut G. Koenigsberger (eds.), Neostoicism and the Early Modern State, Cambridge: Cambridge University Press, 1982 (traducido por David McLintock), pp. 258-273.

12 Philip S. Gorski, The Disciplinary Revolution. Calvinism and the Rise of the State in Early Modern Europe, Chicago / London: University of Chicago Press, 2003.

13 Bernardo García Martínez, "Encomenderos españoles y British residents. El sistema de dominio indirecto desde la perspectiva novohispana": Historia Mexicana, 60: 4 (2011), pp. 1915-1978.

14 Horst Pietschmann, “Diego García Panés y Joaquín Antonio de Rivadeneira Barrientos, pasajeros en un mismo barco. Reflexiones en torno al México 'Imperial' entre 1755 y 1808": Alicia Mayer / Amaya Garritz (eds.), Un hombre de libros. Homenaje a Ernesto de La Torre Villar, México: UNAM, 2012, pp. 211-233; Christian Hausser / Horst Pietschmann, "Empire. The Concept and Its Problems 
menos algunos historiadores sociales y culturales mantienen el argumento de cambios sustanciales, especialmente en el siglo XVIII. A decir de estos autores, los virreyes negociaron con las élites en sus cortes, ${ }^{15} \mathrm{y}$ beneficiaron a sus criados y a los americanos leales, aunque a finales del siglo XVII el padronazgo virreinal dio paso a un mayor poderío real. ${ }^{16}$ Incluso el análisis cultural supone que en este periodo las celebraciones de los monarcas eclipsaron los rituales virreinales en el conjunto de un estado más unificado. ${ }^{17}$

Falta aclarar ¿qué significaba la negociación dentro de un imperio? En las fuentes se utilizó tanto el latín 'negotium', que se derivó de 'nec otium' (sin ocio), como 'negocio' y 'negociación' / 'negociação' en sentidos similares. Significaban principalmente una molestia o cualquier ocupación incluyendo el comercio o asuntos de gobierno, a la cual se sumó la noción de 'negociación' / 'negociação' como “conferir para llegar a un acuerdo". ${ }^{18}$ Hoy en día, los académicos argumentan que los negociadores buscan repartir entre ellos un bien o un 'surplus' de manera que maximicen sus ganancias. Esta división no necesariamente

in the Historiography on the Iberian Empires in the Early Modern Age": Culture \& History Digital Journal, 3: 1 (2014).

15 Francesca Cantú (ed.), Las cortes virreinales de la monarquía española. América e Italia. Actas del Coloquio Internacional. Sevilla, 1-4 de junio de 2005, Roma: Viella, 2008; Lara Sembolini, La construcción de la autoridad virreinal en Nueva España. 1535-1595, México: El Colegio de México, 2014.

16 Christoph Rosenmüller, Corruption and Justice in Colonial Mexico. 1650-1755, Cambridge: Cambridge University Press, 2019, pp. 123-152.

17 Como ejemplos, Pilar Gonzalbo Aizpuru, "Las fiestas del pasado": Enrique Florescano / Bárbara Santana Rocha (eds.), La fiesta mexicana, México: Fondo de Cultura Económica, 2016, pp. 177-181; Frances Ramos, Identity, Ritual, and Power in Colonial Puebla, Tucson: University of Arizona Press, 2012; Linda A. Curcio-Nagy, The Great Festivals of Colonial Mexico City. Performing Power and Identity, Albuquerque: University of New Mexico Press, 2004; Antonio Rubial García, "Las virreinas novohispanas. Presencias y ausencias": Estudios de Historia Novohispana, 50 (2014), pp. 3-44.

18 Diego Jiménez Arias, Lexicon ecclesiasticum latino-hispanicum. Ex sacris Bibliis, conciliis, pontificum decretis, ac theologorum placitis divorum vitis, varii dictionariis, aliisque probatissimis scriptoribus concinnatum, servata ubique vera etymologiae, ortographiae, et accentus ratione, Girona: Narcissum Oliva, 1792, p. 284; Real Academia Española [RAE], 1734, p. 660; Merriam-Webster Dictionary, "negotiate", en línea: https://www.merriam-webster.com/dictionary/negotiate [06-11-2020]. 
significa que ambos partidos recibieran la mitad del bien, ya que la parte más poderosa o menos adversa al riesgo bien puede sacar más provecho. Las partes también reúnen varias ofertas para contrarrestar la información asimétrica sobre el valor de un bien. Mientras tanto, las negociaciones se dificultan cuando una parte sobrevalora su posición por el "sesgo egoísta (self-serving bias)", e incluso en el caso del "sesgo de pastel fijo (fixed-pie bias)", los partes asumen que cualquier ventaja para la parte contraria significa una pérdida para ellos mismos. ${ }^{19}$

Estos conceptos actuales permiten entender la actuación de negociadores modernos que pueden poner fin a las consultas, mientras las negociaciones en el imperio no contaban con igual espacio para maniobrar. Por ejemplo, la Corona exigió un alza sustancial de pagos por el cabezón de alcabalas de la ciudad de México en 1754 sin ofrecer algo nuevo al consulado de México, que administraba el impuesto. El consulado mejoró su oferta; es decir, no era un 'fixed-pie bias', ya que sabía que perdería ingresos si la Corona contrataba a otro administrador de las alcabalas, como había ocurrido en el pasado. La Corona además consiguió otras ofertas que le permitieron entender mejor el valor del cabezón y rechazó la oferta del consulado. Al romperse las negociaciones, la Corona dejó de buscar un consenso y nombró oficiales reales para la recaudación. ${ }^{20}$ En otro caso, un alcalde mayor con algo de "sesgo egoísta" se enfrentó a orgullosos indígenas en la remota Tehuantepec y causó una revuelta en 1660. Estas revueltas del antiguo régimen bien podrían considerarse como costos de regateo ('haggling costs'), que señalaron la voluntad endurecida de un partido en un conflicto. ${ }^{21}$ Finalmente, un ejemplo de una negociación exitosa sobre un surplus se produjo durante el gobierno del conde de Ricla (1763-1766), que reformó las alcabalas al ofrecer importantes

19 Abhinay Muthoo, "A Non-Technical Introduction to Bargaining Theory": World Economics, 1: 2 (2000), pp. 147-162; Cathie Jo Martin, "Negotiating Political Agreements": Jane Mansbridge / Cathie Jo Martin (eds.), Political Negotiation. A Handbook, Washington, D.C.: Brookings Institution Press, 2015, pp. 9-11.

20 Conde de Revillagigedo, Reglamento para la Administración y cobranza de los Reales derechos de Alcabalas, unión de armas y armada de Barlovento, dispuesto y mandado observar por D. Juan Francisco Güemes y Horcasitas, Conde de Revillagigedo, Virrey de Nueva España, México, 26 de septiembre de 1753, Biblioteca Nacional de España, Manuscritos 10358, 476, vol. 4, 2, fols. 23-24.

21 Brian Owensby, Empire of Law and Indian Justice in Colonial Mexico, Stanford: Stanford University Press, 2008, pp. 252-255, 282-285. 
concesiones comerciales a las élites de la Habana. De esta manera, las dos partes se beneficiaron. ${ }^{22}$

Grafe y Irigoin llevan el argumento más allá, ya que "las relaciones entre la Corona y el sujeto se basaban en derechos y deberes mutuos que tenían un precio". ${ }^{23}$ Es una observación importante; además, era la naturaleza del antiguo régimen que la Corona no podía fácilmente rescindir privilegios y tradiciones, a menudo carecía de poder local para hacer cumplir con una resolución y los opositores demoraban un mandamiento a través de largos pleitos judiciales. Sin embargo, las corporaciones o reinos no negociaron a la par con la Corona u otras autoridades y se enfrentaron con restricciones considerables. La Corona, el virrey, o un obispo podían amenazar con visitas o castigos, quitar contratos como el cabezón, negar favores e imponer mandatos. Los autores de este dosier aportan varios ejemplos de estos momentos autoritarios.

Los cinco artículos examinan este campo de tensión del cambio imperial a través de la negociación desigual y el ejercicio de la autoridad. El historiador Gibrán Bautista y Lugo (México) analiza las facetas de negociaciones multicéntricas. Propone que al final del siglo XVI y al principio del siglo XVII, cuatro ciudades capitales resistieron el alza de los impuestos y llegaron a un acuerdo con la Corona o a una solución violenta. El cabildo secular de Quito se rebeló en 1592 hasta que un visitador-general acordó la recaudación de las alcabalas, mientras tropas reales ejecutaron a once revoltosos. En Oporto (Portugal), varios regidores demandaron liberar de impuestos a los importadores de sal, mientras la Corona amenazó con llevar a cabo investigaciones, al final los participantes tomaron en cuenta ambos intereses. En el tercer caso, el arzobispo medió entre el virrey y el cabildo secular de México para aprobar la Unión de Armas y aumentar la alcabala. Finalmente, en Nápoles (Italia) en 1633-1634, el virrey y la aristocracia urbana bajaron la deuda del tribunal de justicia y gobierno a cambio de un pago de 600 mil ducados para la Corona, cantidad que recayó en gran parte en las comunidades y barones rurales opuestos a la aristocracia urbana.

Por otra parte, los individuos ayudaron a la Corona en aplicar sus políticas y enfatizaron sus propias contribuciones para recibir premios,

22 Kuethe / Andrien, The Spanish Atlantic, pp. 241-242, 247, 251.

23 Grafe / Irigoin, “A Stakeholder Empire”, p. 629. 
argumenta el historiador Adolfo Polo y la Borda (Bogotá, Colombia). Cientos de soldados, letrados y ministros circularon a través del Imperio, donde ocuparon plazas, impartieron justicia, obtuvieron para ellos una mejor vida, y se promovieron en escritos e imágenes. Por ejemplo, Juan Francisco Montemayor ocupó una plaza en Santo Domingo antes de convertirse en oidor de México en 1658, donde reprimió la rebelión de los indios de Tehuantepec en 1660. Más tarde, comisionó su retrato que lo muestra con la tradicional golilla negra española como jurista, pero igualmente plasma un yelmo que representa su experiencia militar en Tehuantepec y al luchar contra la rebelión de los catalanes entre 1642 y 1645.

El investigador Miguel Rodrigues Lourenço (Lisboa, Portugal) analiza los conflictos entre Portugal y la Santa Sede sobre el real patronato en Asia (1666-1681) entre Goa (India), Nagasaki (Japón) y las islas de Maluco (Indonesia). Los curas y misioneros bajo el patronato portugués negociaron con la Inquisición la defensa de sus derechos y los de la Corona y excomulgaron a los clérigos de la Congregación de Propaganda Fide, que hasta cierto punto estaban vinculados con el Papa en Roma. Los agentes imperiales usaron el tribunal de la Inquisición para reforzar las ataduras de los territorios con Lisboa, aunque en ocasiones operaban con sus propias agendas, resintieron la gestión de los inquisidores y no faltaron desacuerdos entre esos dos grupos.

Según Christoph Rosenmüller (Murfreesboro, Tennessee, EE. UU.), el virrey marqués de Croix y el visitador general José de Gálvez pusieron fin a las negociaciones en un momento autoritario de 1768. Acusaron a dieciséis sospechosos de oponerse a la expulsión de los Jesuitas de Nueva España. Mientras la historiografía ha calificado a este conjunto como un "partido antigubernativo", el artículo muestra que la mitad de sus integrantes originalmente pertenecían a un grupo progubernativo, ya que recibieron del antiguo virrey primer conde de Revillagigedo (1746-1755) importantes recomendaciones o puestos. Especialmente el canónigo Ignacio Felipe Cevallos ayudó a Revillagigedo para quitar al consulado de México la administración de la alcabala de la ciudad. El artículo demuestra que no sólo los criollos o los indios se opusieron a las reformas de Croix y Gálvez, sino también una antigua red clientelar de procedencia regional variada. Este tema del peso que tuvieron las poderosas redes sociales ha sido abordado por los historiadores desde la década de los 70, aunque se han alejado últimamente de una visión 
demasiado determinista. Al día de hoy, se concuerda que las redes eran a menudo inestables al grado de que algunas personas de las élites conservaron un margen considerable para la toma de decisiones. ${ }^{24}$

El historiador David Rex Galindo (Santiago de Chile) argumenta que entre 1785 y 1795, fray Pedro González de Agüeros buscaba beneficiar tanto a su orden religiosa como construir el Estado desde los márgenes del Imperio $-\mathrm{y}$ esto durante un periodo en que las órdenes se encontraban en decadencia tras perder casi todas sus doctrinas (es decir, los curatos en comunidades indígenas) en América. González de Agüeros, franciscano del colegio de la Congregación de Propaganda Fide en Ocopa, informó a Madrid sobre el áspero y remoto archipiélago de Chiloé y la frontera austral (Chile). Afín al discurso del reformismo borbónico, el franciscano combinaba un novedoso método misionero con sugerencias para la mejora de las defensas militares y el progreso económico y educativo de las poblaciones hispanas e hispanizadas. Sus reportes convencieron a las autoridades locales y virreinales que le brindaron apoyo.

Los estudios de caso muestran que de forma gradual $-\mathrm{y}$ no siempre con gran resultado- se intentó llevar a cabo reformas de diversas índoles y direcciones ya desde el tardío siglo XVI. En muchos casos, la Corona u otras autoridades llegaron a un consenso con grupos locales para repartir el surplus, pero también había series de acciones autoritarias, cuando la Corona se alió con fuerzas locales para quebrar la resistencia. Para este fin, Madrid y Lisboa dividieron la oposición y ofrecieron beneficios para agentes imperiales y colaboradores locales leales que esperaban avanzar socialmente. Además, amenazaron con investigaciones y castigaron a los opositores con detenciones, deportaciones o incluso ejecuciones, cuando había resistencia manifiesta contra la Corona. Las redes sociales y las corporaciones, poderosos actores del antiguo régimen, frenaron o apoyaron las exigencias metropolitanas o del clero reformador, pero no detuvieron completamente el proceso. Con estos resultados, las aportaciones al

24 Michel Bertrand, "Del actor a la red. Análisis de redes e interdisciplinariedad": Evelyne Sanchez (ed.), Los actores locales de la nación en la América Latina. Análisis estratégicos, Puebla, México: Benemérita Universidad Autónoma de Puebla / Tlaxcala, México: El Colegio de Tlaxcala, 2011, p. 39; Zacarías Moutoukias, "Negocios y redes sociales. Modelo interpretativo a partir de un caso rioplatense (siglo XVIII)”: Caravelle, 67 (1997), pp. 37-55. 
dosier se despiden hasta cierto punto de la perspectiva historiográfica clásica de que haya ocurrido poco en los imperios hasta el siglo XVIII.

Jahrbuch für Geschichte Lateinamerikas | Anuario de Historia de América Latina 